\title{
Влияние перекиси водорода на фотоанодирование $n$-Si в режиме пробоя
}

\author{
(С) Г.В. Ли, Е.В. Астрова, А.И. Лихачев \\ Физико-технический институт им. А.Ф. Иофрфе Российской академии наук, \\ 194021 Санкт-Петербург, Россия \\ E-mail: east@mail.ioffe.ru
}

(Получена 23 апреля 2018 г. Принята к печати 25 мая 2018 г.)

\begin{abstract}
Проведено экспериментальное исследование анодного растворения низколегированного $n$ - $\mathrm{Si}(100)$ в электролите, состоящем из 4\% раствора $\mathrm{HF}$ в $30 \%$ перекиси водорода, при напряжении выше напряжения пробоя. Изучено влияние величины освещенности обратной стороны пластины на морфологию пористой структуры и на такие параметры, как пористость, эффективная валентность и скорость роста пор. Полученные данные сравниваются с данными для структур, подвергшихся фотоанодированию в водном электролите с той же концентрацией HF. Установлено, что наличие перекиси водорода значительно меняет морфологию макропор, уменьшает их диаметр и увеличивает в $\sim 2$ раза скорость роста в глубь подложки. В присутствии $\mathrm{H}_{2} \mathrm{O}_{2}$ наблюдается появление наклонных вторичных пор, ориентированных под углом $15-35^{\circ}$ к оси основного канала, и увеличение числа пробойных мезопор, распространяющихся в направлениях $\langle 100\rangle$ в плоскости, параллельной поверхности образца. Эффективная валентность электрохимического растворения кремния в электролите $\mathrm{HF}: \mathrm{H}_{2} \mathrm{O}_{2}$ при низком уровне подсветки близка к единице и возрастает с интенсивностью света, оставаясь всегда меньше 2.
\end{abstract}

DOI: 10.21883/FTP.2018.13.46876.8898

\section{1. Введение}

Метод электрохимического травления кремния в плавиковой кислоте на сегодняшний день широко применяется для различных областей науки и техники [1], поскольку позволяет получать пористые материалы с различной морфологией пор, путем выбора определенных параметров электрохимического травления (анодирования) и характеристик материала. По размеру пор пористые материалы принято делить на микро$(<2 \mathrm{Hм})$, мезо- (от 2 до $50 \mathrm{Hм})$ и макро- $(\geq 50 \mathrm{Hм})$ пористые. Особую нишу занимает макропористый кремний, поскольку его поры имеют гладкие вертикальные стенки и являются удобной основой для формирования различных микро- и наноструктур [2]. Макропоры чаще всего получают на $n$-Si с низким уровнем легирования в условиях подсветки обратной стороны анодируемого образца при невысоких напряжениях 1-2 В в водных электролитах с малой концентрацией $\mathrm{HF}[3,4]$. При отсутствии освещения формирование пористой структуры в $n$-Si становится возможным только при достаточно высоком напряжении, при котором в результате пробоя появляются электронные дырки. При этом в образце формируется иерархическая структура пор, которая представляет собой основной канал, ориентированный перпендикулярно анодируемой поверхности (100), и боковые ветви, представляющие собой вторичные поры меньшего диаметра (эффект ветвления) [5]. Недавно в работе [6] было показано, что управлять образованием иерархической структуры можно с помощью света, который подавляет пробой на дне каналов.

Перекись водорода используется как окислитель в составе фторсодержащего раствора при получении пор бестоковым методом в присутствии катализаторов из благородных металлов (metal assisted electrochemical etching MECE) [7] и для приготовления пористого кремния с использованием внутреннего источника тока [8]. До недавнего времени влияние окислителей на процесс электрохимического растворения $n-\mathrm{Si}$ изучался только при отсутствии освещения [9-15]. Анодирование при освещении в электролите, содержащем $\mathrm{H}_{2} \mathrm{O}_{2}$, стало исследоваться в работах группы Barillaro $[6,16,17]$. В первой из них [6] показано, что добавление перекиси водорода в электролит с высокой концентрацией HF при фотоанодировании приводит к усиленному образованию вторичных пробойных мезопор по сравнению с водным электролитом. В двух других работах $[16,17]$ исследовано ускоренное травление регулярных макропор при низких напряжениях (вне области пробоя) в растворах $\mathrm{HF}: \mathrm{H}_{2} \mathrm{O}_{2}$ с малым содержанием плавиковой кислоты.

В настоящей работе основное внимание уделено изучению влияния света на процесс анодирования электронного кремния в пробойном режиме при использовании электролита с высоким содержанием окисляющего агента $\mathrm{H}_{2} \mathrm{O}_{2}$. Проводится сравнение процесса образования неупорядоченных макропор в 4\% растворе $\mathrm{HF}$ в 30\% перекиси водорода и в воде с той же концентрацией плавиковой кислоты. Определены зависимости морфологии пор, пористости, скорости травления и эффективной валентности анодного растворения кремния от интенсивности подсветки обратной стороны образца.

\section{2. Эксперимент и его результаты}

Исходным материалом служили предварительно текстурированные пластины монокристаллического крем- 


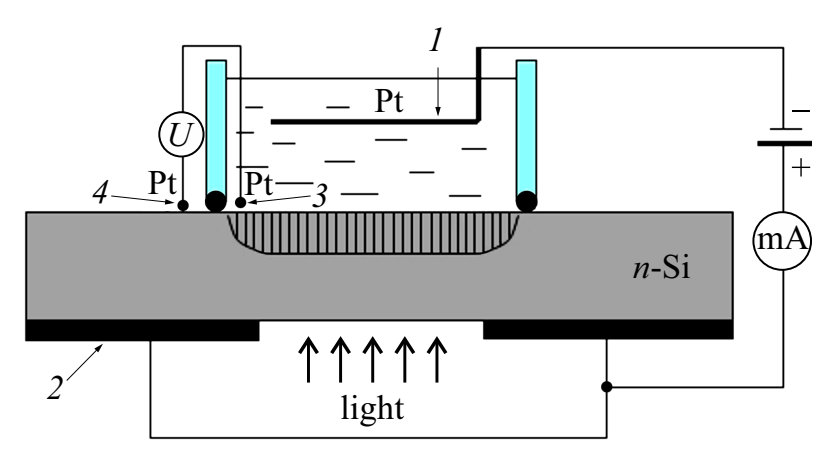

Рис. 1. Схема ячейки для фотоэлектрохимического травления.

ния $n-\mathrm{Si}(100)$ с удельным сопротивлением 3 Ом·см, предназначенные для изготовления солнечных элементов. Эксперименты проводились в электрохимической ячейке (рис. 1) с помощью установки SiPor фирмы ET\&TE (подробности эксперимента см. в работе [18]).

Анодирование области диаметром 19 мм осуществлялось в условиях освещения обратной стороны образца. Освещение контролировалось путем изменения напряжения $E$, подаваемого на светодиодную матрицу, состоящую из $7 \times 7$ инфракрасных светодиодов, излучающих свет с длиной волны 0.88 мкм. В процессе электрохимического травления записывалось изменение во времени $t$ величины протекающего тока $I$, напряжения на границе $\mathrm{Si}-$ электролит $U$ и напряжения $E$ на светодиодах. Эксперименты проводились с использованием двух разных электролитов: 1) 4\% раствора $\mathrm{HF}$ в 30\% перекиси водорода (перекисный электролит) и 2) 4\% раствора НF в воде (водный электролит). $\mathrm{B}$ оба электролита для лучшей смачиваемости кремния добавлялось $5 \% \mathrm{C}_{2} \mathrm{H}_{5} \mathrm{OH}$.

Измерение вольт-амперных характеристик показало, что напряжение холостого хода для перекисного электролита сдвинуто в катодную сторону относительно водного электролита: $U_{O C}=-1.1$ и $-0.5 \mathrm{~B}$ соответ-

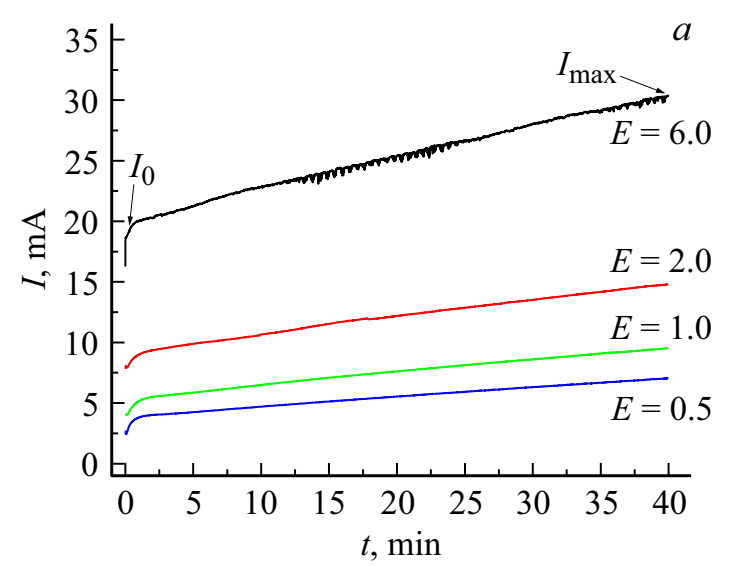

ственно. Эти данные хорошо согласуются с данными работы [16], где для 5\% НF раствора с максимальной и нулевой концентрацией $\mathrm{H}_{2} \mathrm{O}_{2}$ эти значения составляли -1.0 и $-0.5 \mathrm{~B}$ соответственно. Для нашего кремния для обоих электролитов резкое возрастание темнового тока, указывающее на пробой, начиналось при напряжении $U>8$ В. Эксперименты по влиянию интенсивности света проводились в потенциостатическом режиме при фиксированном напряжении $U=12 \mathrm{~B}$, которое было выше напряжения пробоя. Длительность процесса составляла 40-70 мин, температура анодирования $15^{\circ} \mathrm{C}$. Пористость определяли гравиметрическим методом по формуле $p=\frac{\Delta m}{\rho_{\mathrm{Si}} \cdot l \cdot S}$, где $\rho_{\mathrm{Si}}=2.33$ г $/ \mathrm{cm}^{3}-$ плотность кремния, $S=2.83 \mathrm{~cm}^{2}$ - площадь анодируемой области, $l$ - глубина пористого слоя. Последнюю определяли с помощью оптического микроскопа Nikon LV150 после раскалывания образца. Эффективную валентность $n$ (выход по току) находили с помощью закона Фарадея как отношение количества электричества $Q$ к массе растворенного кремния $\Delta m: n=k \cdot Q / \Delta m$, где $k=2.91 \cdot 10^{-4} \Gamma /(\mathrm{A} \cdot \mathrm{c})$. Скорость травления находили путем деления глубины пористого слоя на продолжительность анодирования $r=l / t$.

На рис. 2 приведены зависимости тока анодирования от времени. Из рисунка видно, что для обоих электролитов ток травления линейно возрастает во времени от начального значения $I_{0}$ до максимального $I_{\max }$. При этом в водном электролите наблюдаются колебания тока (рис. 2, $b$ ). Эти колебания отсутствуют в начальный период травления $t \sim 10-15$ мин, которое, по-видимому, соответствует фазе зарождения пор. Обращает на себя внимание тот факт, что при повышении интенсивности света амплитуда колебаний имеет тенденцию уменьшаться, а начало перехода в режим колебаний сдвигаться в сторону бо́льших $t$. Поскольку в процессе травления при низких напряжениях колебаний тока не возникает, это позволяет заключить, что их появление связано с пробоем. Из рис. 2 также видно, что наклон зависимостей $I(t)$ увеличивается по мере возрастания

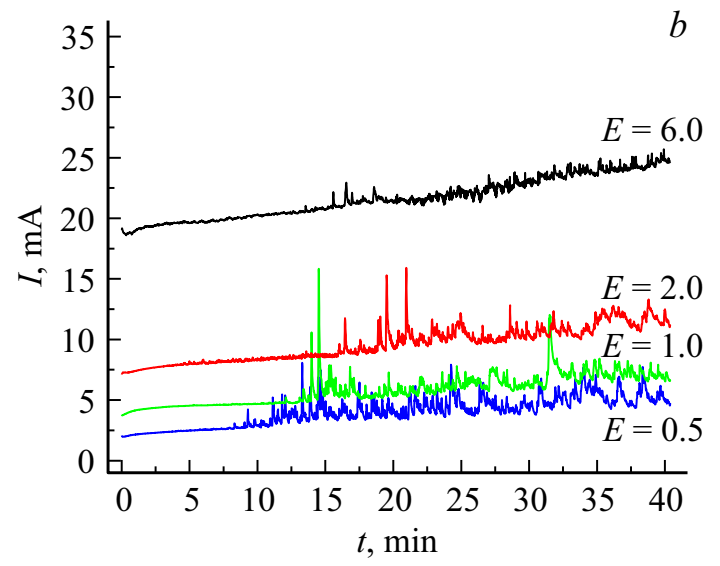

Рис. 2. Характерные зависимости тока травления от времени при разной подсветке $E$ при $U=12$ В в перекисном $(a)$ и в водном $(b)$ электролите. 

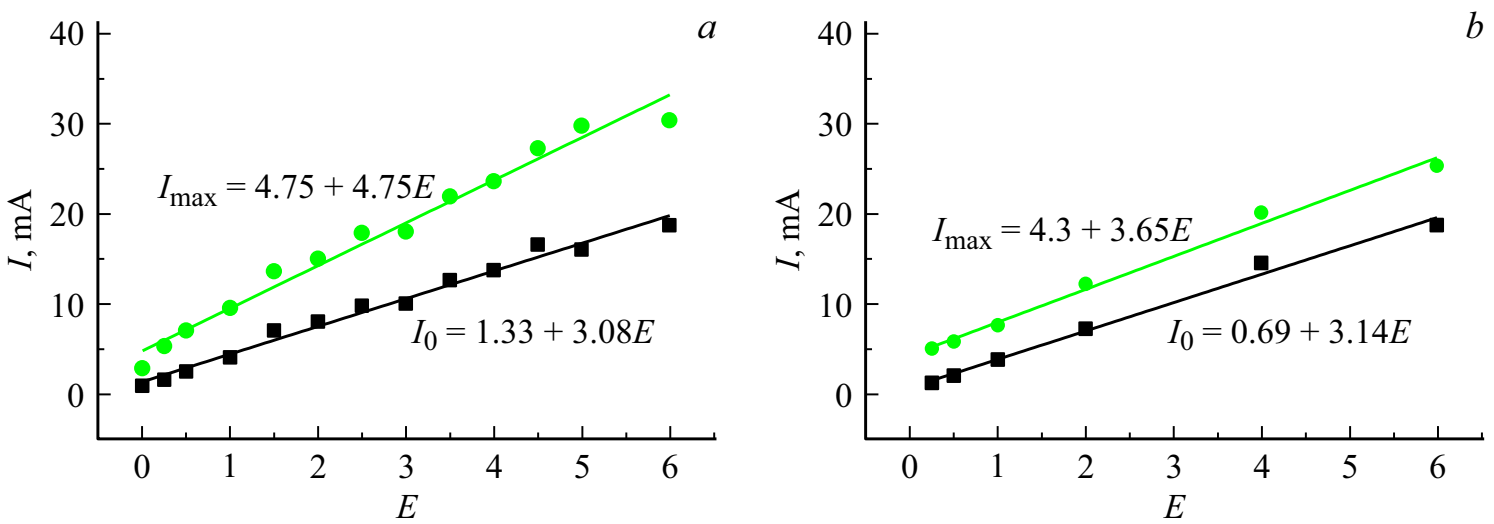

Рис. 3. Зависимость начального и максимального токов от интенсивности подсветки $(U=12 \mathrm{~B}, t=40$ мин $)$ для электролитов на основе перекиси водорода $(a)$ и воды $(b)$.

интенсивности подсветки, при этом для перекисного электролита этот наклон больше.

На рис. 3 приведены зависимости начального и максимального токов от интенсивности подсветки для обоих электролитов. Видно, что абсолютные значения токов для перекиси несколько выше, чем для воды. Следует обратить внимание, что наклон прямых $I_{0}(E)$ для перекиси и воды практически одинаков (3.08 и 3.14 соответственно). Это говорит о том, что для обоих электролитов начальный фототок прямо пропорционален интенсивности света. Постоянный член в уравнении прямой $I_{0}(E)$ определяется величиной темнового тока. Для перекиси $I_{0}(E=0)$ в $\sim 2$ раза выше, чем для воды: $1.33 \mathrm{MA}\left(j_{s c}=0.47 \mathrm{MA} / \mathrm{cm}^{2}\right)$ по сравнению с $0.69 \mathrm{MA}$ $\left(j_{s c}=0.24 \mathrm{MA} / \mathrm{cm}^{2}\right)$. В уравнениях кривых $I_{\max }(E)$ разница в коэффициентах перед $E$ существенна, и больше для перекиси. По-видимому, это связано с более развитой поверхностью.

В табл. 1 и 2 приведены параметры слоев, полученных в двух разных электролитах, где $l-$ глубина травления, $j_{a v}$ - среднее значение плотности тока за время травления, $\Delta m$ - масса растворившегося при анодировании кремния, $n$ - эффективная валентность. Поскольку скорость анодирования в перекисном электролите заметно больше, чем в водном, то для получения сравнимых по глубине пор и анализа их морфологии электрохимическое травление в водном электролите проводилось дольше: 70 мин вместо 40.

На рис. 4-7 в разном масштабе приводится изображение поперечного сечения исследуемых образцов, полученное с помощью растрового электронного микроскопа JSM-7001F, Jeol, Япония. Поперечное сечение представляет собой плоскость (110). Из рис. 4 и 6 видно, что для электролита на основе перекиси водорода при $E=0$ пористая структура типична для той, что обычно наблюдается для пробоя в темноте [3,5,11-13]. Она состоит из основных пор, которые представляют собой тонкие вертикальные каналы, заостренные книзу, и вторичных пор меньшего диаметра, распространяющиеся в горизонтальной плоскости. Эти вторичные поры имеют огранку плоскостями $\langle 111\rangle$ и, по-видимому, идентичны октаэдрическим мезопорам, наблюдавшимся в работах [19-21], далее мы будем их называть пробойными

Таблица 1. Параметры пористых слоев, полученных при разном освещении в электролите на основе перекиси водорода при $U=12$ В в течение $t=40$ мин

\begin{tabular}{c|l|c|c|c|c|c|c}
\hline $\begin{array}{c}\text { № } \\
\text { образца }\end{array}$ & $\begin{array}{c}E, \\
\text { В }\end{array}$ & $\begin{array}{c}p, \\
\%\end{array}$ & $\begin{array}{c}l, \\
\text { мкм }\end{array}$ & $\begin{array}{c}r, \\
\text { мкм/мин }\end{array}$ & $n$ & $\begin{array}{c}j_{a v}, \\
\text { мА/см² }\end{array}$ & $\begin{array}{c}\Delta m, \\
\text { мг }\end{array}$ \\
\hline 13A4 & 0 & 5 & 49 & 1.23 & 0.84 & 0.68 & 1.6 \\
12M2 & 0.25 & 7 & 56 & 1.40 & 1.07 & 1.41 & 2.6 \\
25A5 & 0.5 & 9 & 59 & 1.48 & 1.10 & 1.94 & 3.5 \\
25A1 & 1 & 10 & 63 & 1.57 & 1.22 & 2.65 & 4.3 \\
25A6 & 1.5 & 14 & 63 & 1.57 & 1.33 & 3.98 & 5.9 \\
11A2 & 2 & 14 & 63 & 1.57 & 1.43 & 4.27 & 5.9 \\
12M1 & 2.5 & 17 & 63 & 1.57 & 1.43 & 5.08 & 7.0 \\
12A1 & 3 & 18 & 64 & 1.6 & 1.36 & 5.23 & 7.6 \\
17M5 & 3.5 & 18 & 64 & 1.6 & 1.64 & 6.32 & 7.6 \\
12A2 & 4 & 23 & 65 & 1.62 & 1.37 & 6.92 & 10.0 \\
17M3 & 4.5 & 19 & 65 & 1.625 & 1.95 & 7.89 & 8.0 \\
25A2 & 5 & 24 & 67 & 1.7 & 1.65 & 8.77 & 10.5 \\
13A1 & 6 & 22 & 66 & 1.65 & 1.84 & 8.93 & 9.6
\end{tabular}

Таблица 2. Параметры пористых слоев, полученных при разном освещении в водном электролите при $U=12$ В в течение $t=70$ мин

\begin{tabular}{c|c|c|c|c|c|c|c}
\hline $\begin{array}{c}\text { № } \\
\text { образца }\end{array}$ & $\begin{array}{c}E, \\
\text { В }\end{array}$ & $\begin{array}{c}p, \\
\%\end{array}$ & $\begin{array}{c}l, \\
\text { мкм }\end{array}$ & $\begin{array}{c}r, \\
\text { мкм/мин }\end{array}$ & $n$ & $\begin{array}{c}j_{a v}, \\
\text { мА/см }\end{array}$ & $\begin{array}{c}\Delta m, \\
\text { мг }\end{array}$ \\
\hline 29In1 & 0 & 19 & 30 & 0.43 & 2.61 & 2.8 & 3.7 \\
29In4 & 0.5 & 11 & 48 & 0.69 & 1.94 & 2.0 & 3.5 \\
29In2 & 1 & 12 & 55 & 0.79 & 2.28 & 2.8 & 4.3 \\
29In5 & 2 & 20 & 57 & 0.81 & 2.25 & 4.9 & 7.5 \\
30In1 & 3 & 24 & 57 & 0.81 & 2.26 & 5.9 & 9.0 \\
29In3 & 4 & 39 & 57 & 0.81 & 2.28 & 9.8 & 14.8 \\
30In2 & 5 & 40 & 57 & 0.81 & 2.26 & 9.9 & 15.1 \\
30In3 & 6 & 44 & 55 & 0.79 & 2.28 & 10.6 & 16.1
\end{tabular}




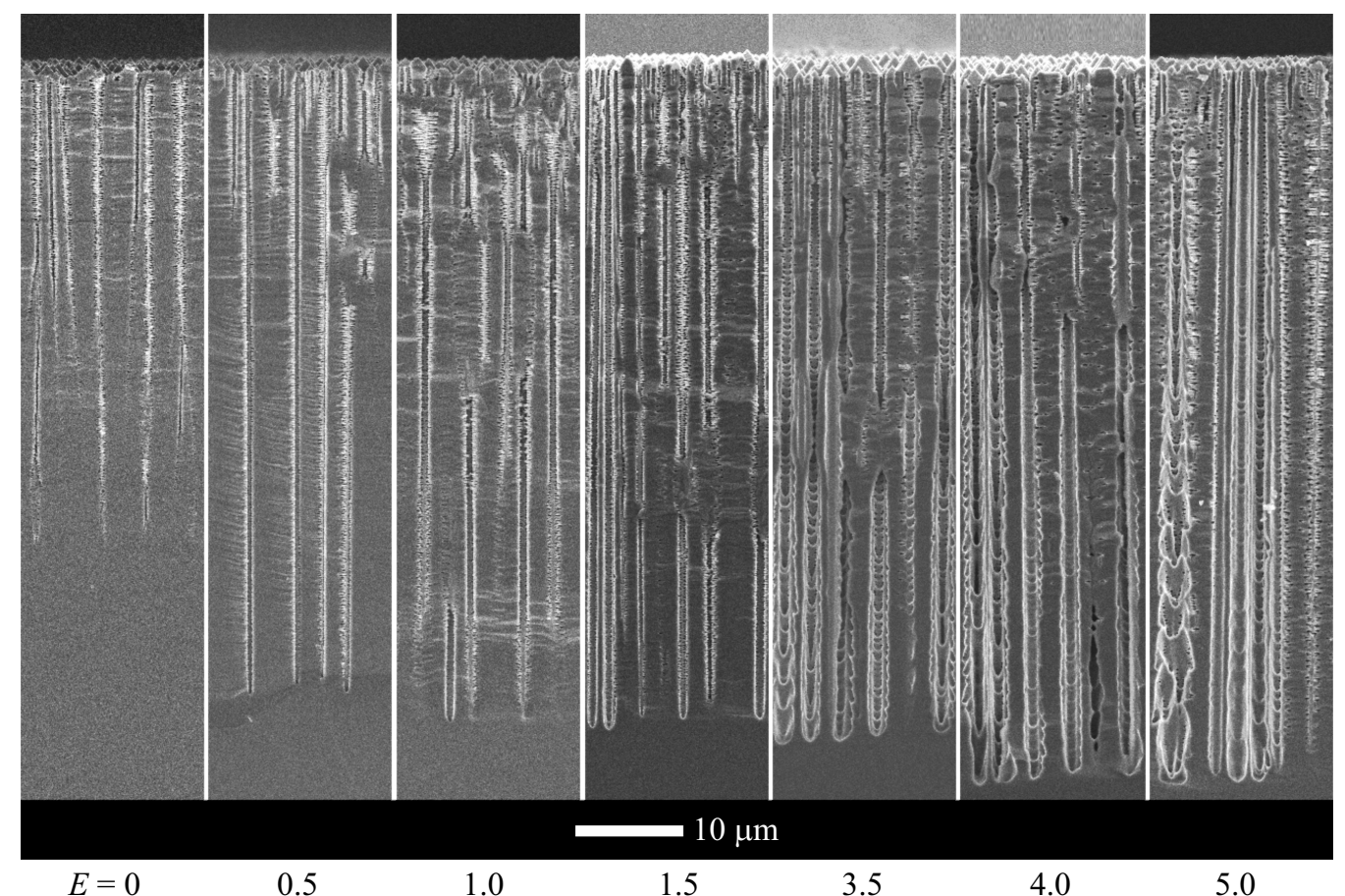

Рис. 4. Зависимость морфологии пор от интенсивности света $E$. Травление в перекисном электролите в режиме $E=$ const при $U=12 \mathrm{~B}, t=40$ мин.

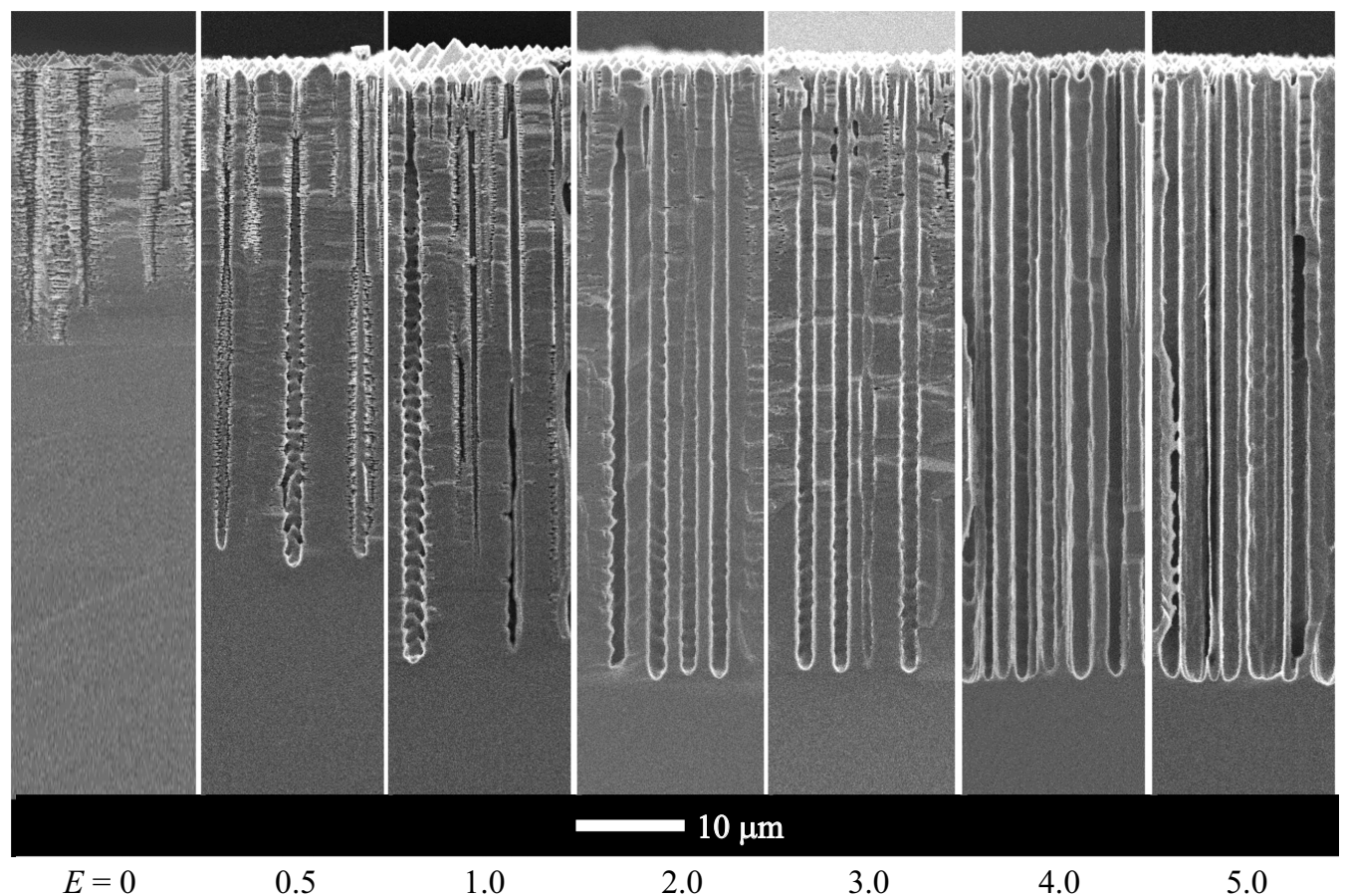

Рис. 5. Зависимость морфологии пор от интенсивности света $E$. Травление в водном электролите в режиме $E=$ const при $U=12 \mathrm{~B}, t=70 \mathrm{мин}$

мезопорами. Диаметр основных каналов уменьшается с глубиной от $d=350$ до $d=200$ нм.

Пористый слой, сформированный в темноте, не имеет плоского фронта на границе с подложкой и обладает невысокой пористостью, всего 5\%. Для водного элек- тролита мы наблюдаем похожую картину с той лишь разницей, что диаметр основного канала и диаметр пробойных мезопор в этом случае больше, а глубина пористого слоя меньше (рис. 5 и 7). По мере увеличения интенсивности света в случае водного электролита по- 


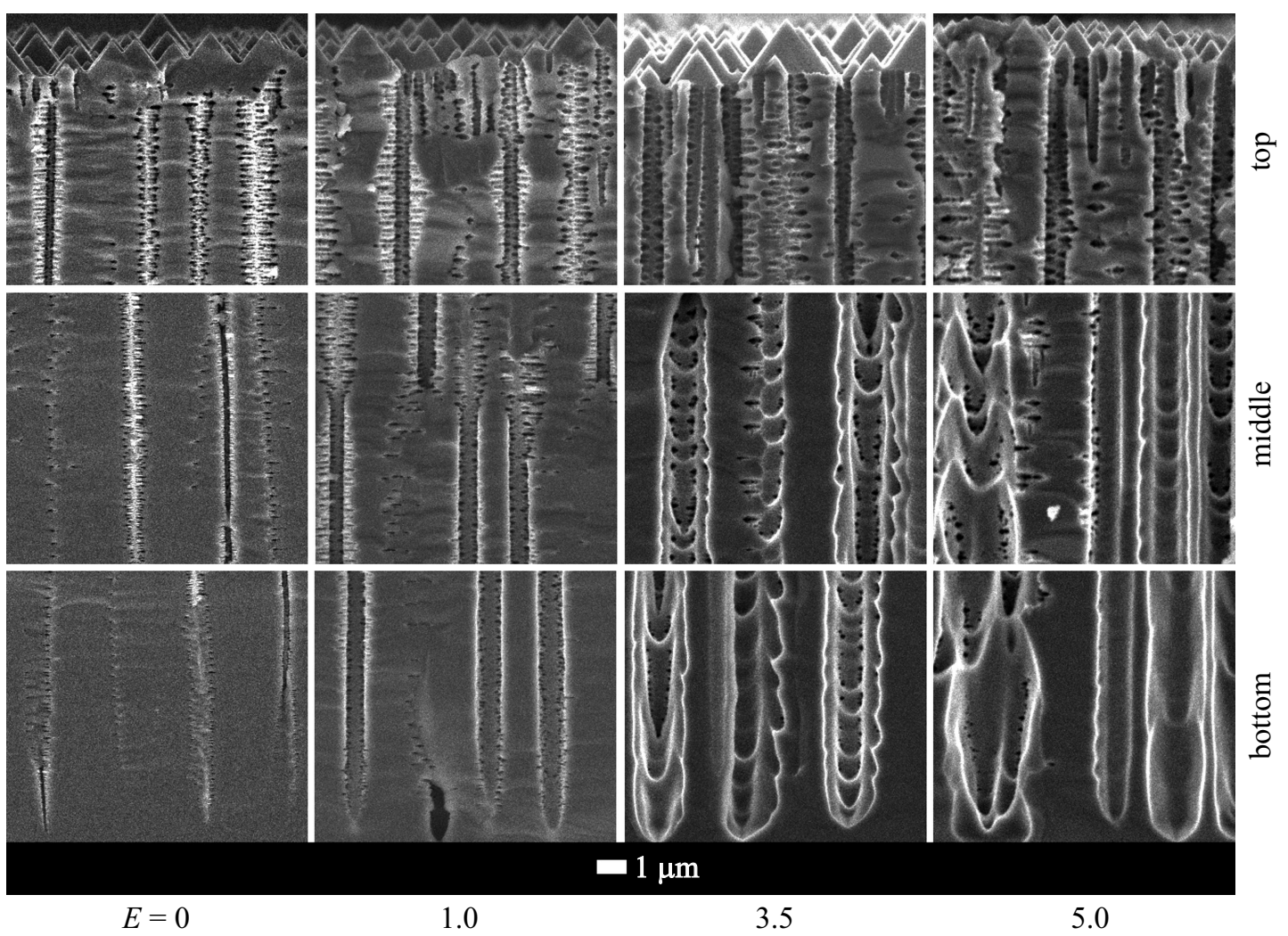

Рис. 6. Увеличенное изображение разных по высоте частей пористого слоя, показанного на рис. 4.
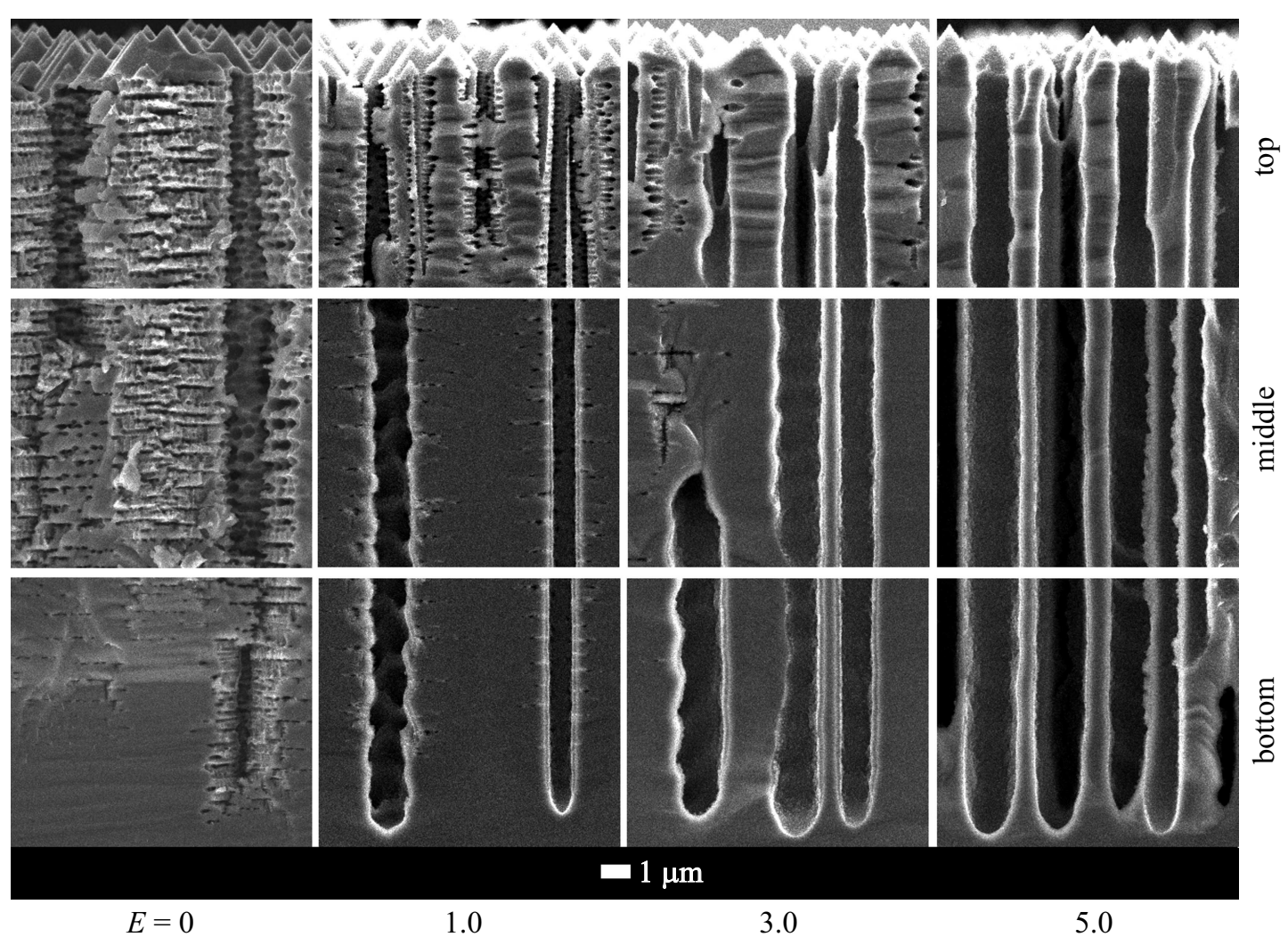

Рис. 7. Увеличенное изображение разных по высоте частей пористого слоя, показанного на рис. 5. 

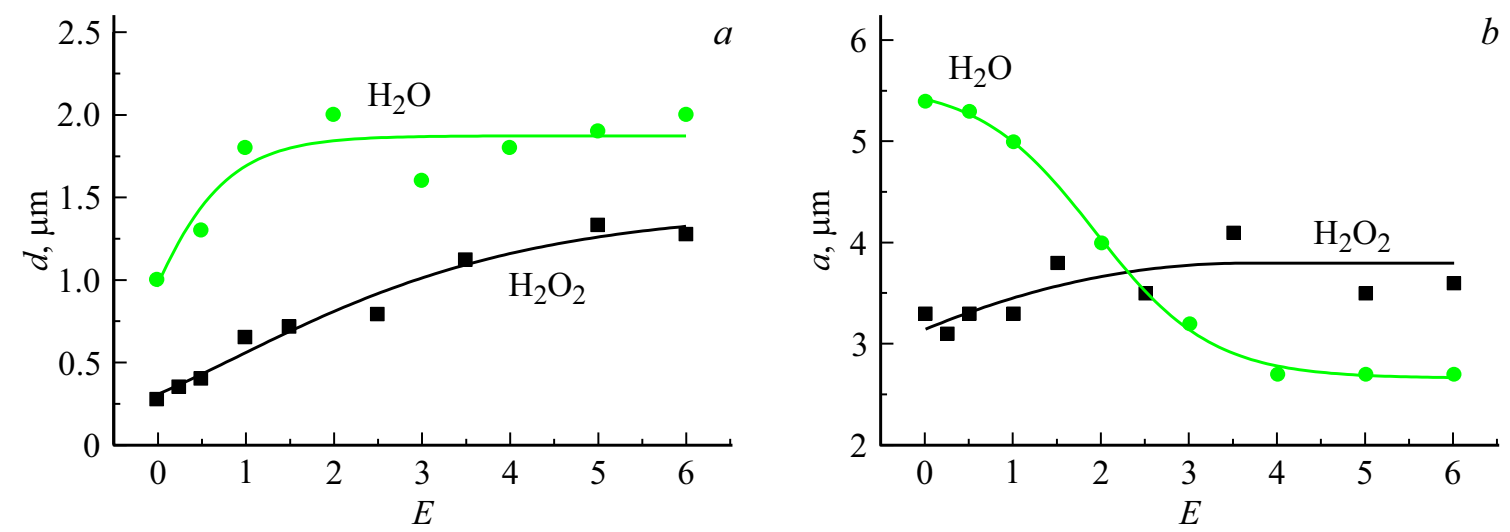

Рис. 8. Зависимость среднего диаметра $(a)$ и периода $(b)$ основных каналов макропор от уровня освещения для двух электролитов, напряжение анодирования $U=12 \mathrm{~B}$.

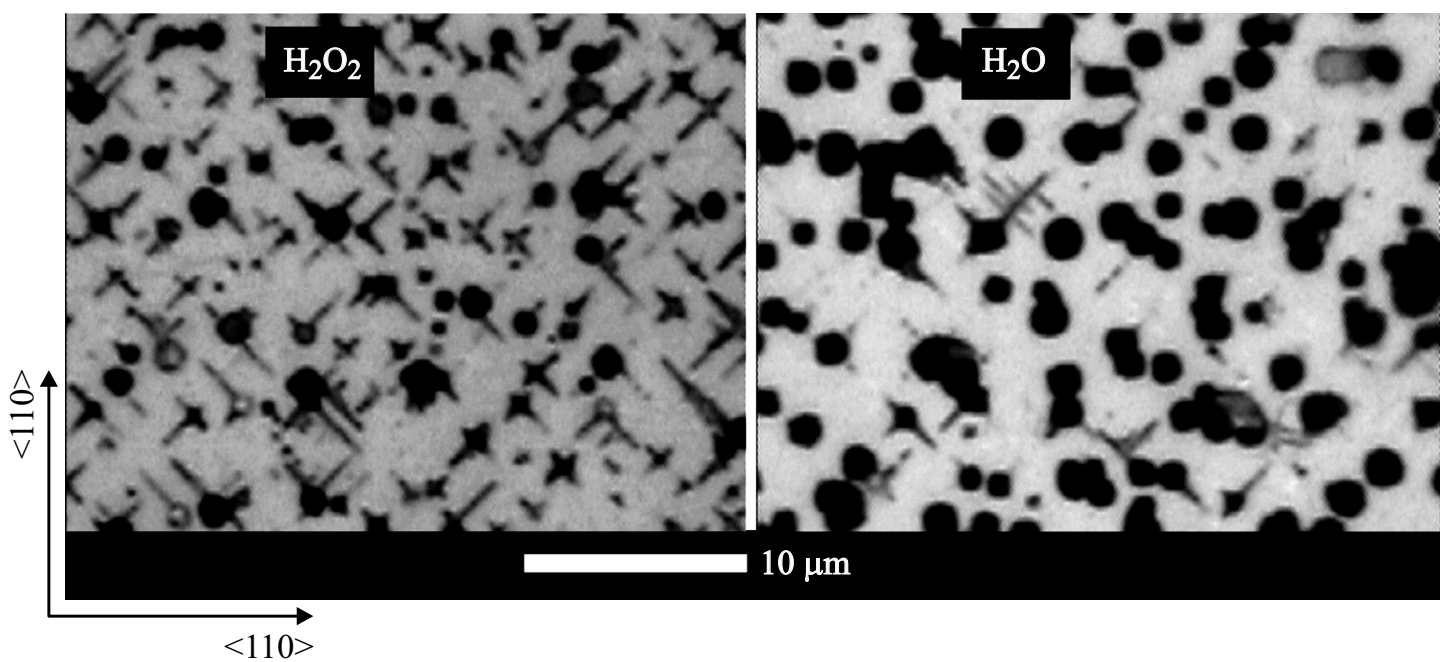

Рис. 9. Изображение поверхности пористых образцов (плоскость (100)), полученных после удаления верхнего слоя $\sim 15$ мкм (слева - результат анодирования в перекисном электролите, справа — в водном).

степенно исчезают пробойные мезопоры и уменышается ветвление основного канала, стенки которого становятся более гладкими. В случае перекиси пробойные мезопоры остаются, а ветвление основного канала даже увеличивается. При этом его диаметр, меньше, чем в случае воды. На рис. 8 показана зависимость среднего значения диаметра основных каналов $d$ и среднего расстояния между ними $a$ для двух сравниваемых электролитов. Измерения проведены на средней по высоте части пор. Видно, что увеличение интенсивности света приводит к возрастанию диаметра $d$ в случае перекисного электролита и стабилизации его в случае водного. Плотность каналов также ведет себя по-разному: для водного электролита расстояние между ними сильно падает, что способствует снижению ветвления, а для перекисного $a$ поначалу немного возрастает, а потом остается на более высоком уровне, чем для водного. По-видимому, процесс нуклеации пор на поверхности в водном и перекисном электролитах происходит по-разному. Для перекисного электролита при $E>3.5 \mathrm{~B}$ мы наблюда- ем появление наклонных вторичных пор, исходящих из основных каналов и ориентированных под углом $15-35^{\circ}$ относительно вертикальной оси. Рост освещения приводит к увеличению их диаметра и периода (рис. 4 и 6). Следует отметить, что форма макропор в случае перекисного электролита гораздо сильнее изменяется с глубиной, чем для водного. Это, по-видимому, связано с обеднением электролита ионами $\mathrm{F}^{-}$из-за расходования их на большей площади пробойных мезопор и из-за более высокого аспектного отношения $(l / d=60$ и 28 соответственно для перекисного и водного электролитов). Число пробойных мезопор с глубиной травления уменьшается как в перекисном, так и в водном электролите.

\section{3. Обсуждение результатов}

Иерархическая пористая структура, формирующаяся при фотоэлектрохимическом травлении кремния в смеси $\mathrm{HF}: \mathrm{H}_{2} \mathrm{O}_{2}$, при напряжении выше пробойного характеризуется каналами меньшего диаметра и более развитой 

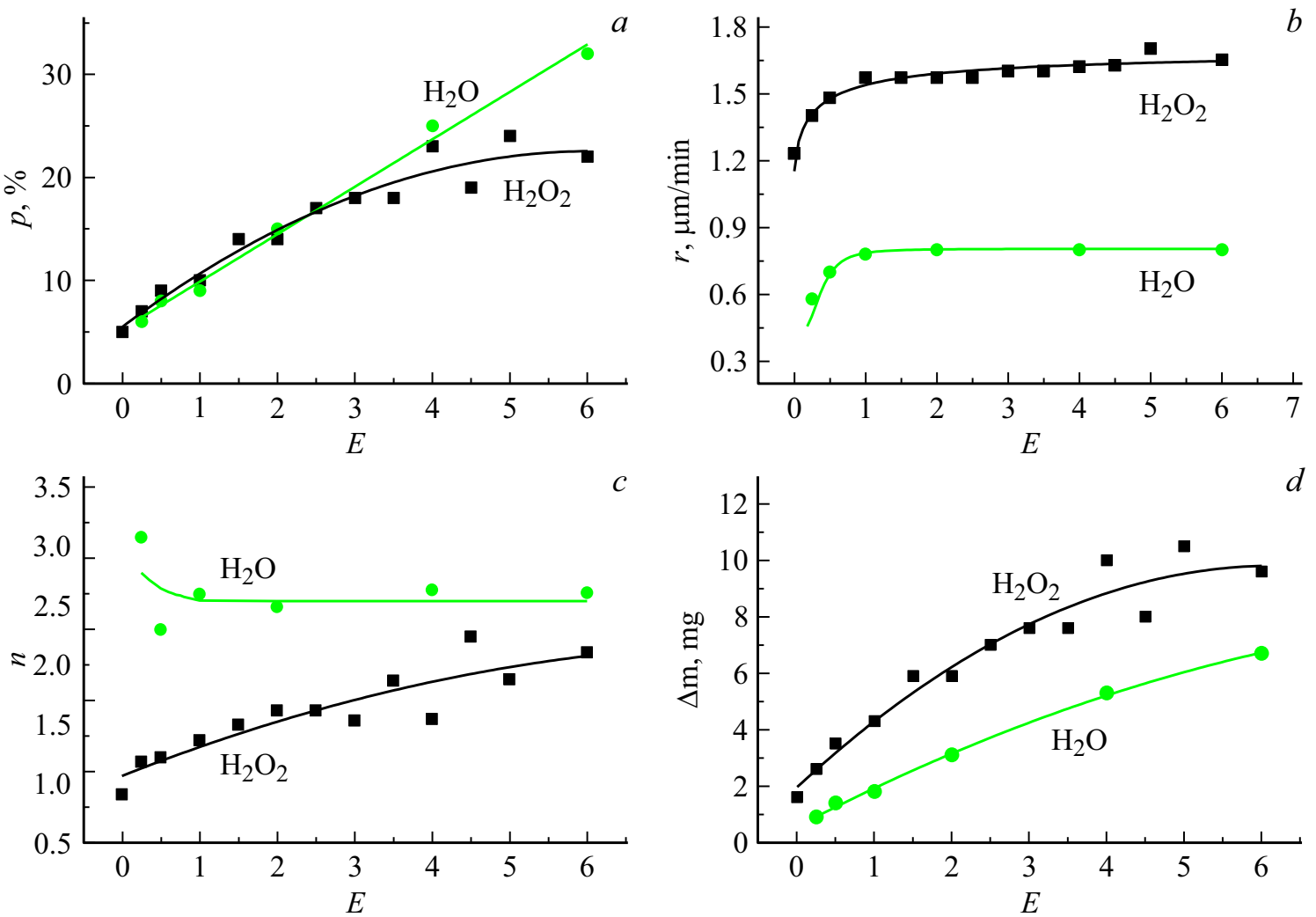

Рис. 10. Зависимость пористости $(a)$, скорости травления $(b)$, валентности $(c)$ и массы растворенного кремния $(d)$ от интенсивности света для двух электролитов при анодировании при $U=12$ В в течение 40 мин.

системой пробойных мезопор, чем при травлении в растворе $\mathrm{HF}: \mathrm{H}_{2} \mathrm{O}$. Таким образом, свет подавляет образование пробойных мезопор в водном растворе НF, но менее эффективен в случае раствора на основе перекиси. В последнем случае ветвление основных каналов по мере увеличения интенсивности света даже, наоборот, возрастает. На рис. 9 приведено изображение поверхности пористых образцов после удаления верхнего слоя $\sim 15$ мкм с помощью шлифовки и полировки. На нем видно, что в случае перекисного электролита диаметр основных каналов макропор меньше, чем в случае водного, а число пробойных мезопор выше. В обоих случаях пробойные мезопоры ориентируются вдоль направлений $\langle 100\rangle$ независимо от состава электролита.

Для сравнения параметров пористых слоев, полученных в разных электролитах, было проведено анодирование в водном электролите при той же длительности процесса, что и для перекисного, т.е. при $t=40$ мин. Полученные параметры приведены в табл. 3. Сравнение табл. 2 и 3 показывает, что при травлении в водном электролите такие величины, как эффективная валентность и скорость роста пор, не зависят от длительности процесса.

Сравнение зависимостей от интенсивности света для двух электролитов: пористости, скорости травления, эффективной валентности и изменения массы образца приведены на рис. 10. Для обоих электролитов пори- стость плавно возрастает с увеличением освещенности. Абсолютные величины пористости при невысоком освещении для обоих электролитов примерно одинаковы (рис. 10,a). Для водного электролита во всем диапазоне измерений сохраняется линейная зависимость $p(E)$, а для перекисного наблюдается замедление скорости ее возрастания, в результате чего при больших освещенностях пористость для перекисного электролита становится меньше, чем для водного. Скорость роста макропор в глубь подложки (рис. 10, $b$ ) для обоих электролитов плавно увеличивается при малой освещенности, а затем при $E>1 \mathrm{~B}\left(j_{a v}>2 \mathrm{MA} / \mathrm{cm}^{2}\right)$ выходит на насыщение. Это свидетельствует о том, что скорость процесса рас-

Таблица 3. Параметры пористых слоев, полученных при разном освещении в водном электролите при $U=12$ В в течение $t=40$ мин

\begin{tabular}{c|l|c|c|c|c|c|c}
\hline $\begin{array}{c}\text { № } \\
\text { образца }\end{array}$ & $\begin{array}{c}E, \\
\text { В }\end{array}$ & $\begin{array}{c}p, \\
\%\end{array}$ & $\begin{array}{c}l, \\
\text { мкм }\end{array}$ & $\begin{array}{c}r, \\
\text { мкм/мин }\end{array}$ & $n$ & $\begin{array}{c}j_{a v}, \\
\text { мА/см }\end{array}$ & $\begin{array}{c}\Delta m, \\
\text { мг }\end{array}$ \\
\hline $8 \mathrm{~N} 3$ & 0.25 & 6 & 23 & 0.58 & 2.65 & 1.2 & 0.9 \\
$8 \mathrm{~N} 2$ & 0.5 & 8 & 28 & 0.70 & 2.00 & 1.4 & 1.4 \\
$8 \mathrm{~N} 1$ & 1 & 9 & 31 & 0.78 & 2.25 & 2.1 & 1.8 \\
3N2 & 2 & 15 & 32 & 0.80 & 2.16 & 3.4 & 3.1 \\
$7 \mathrm{~N}$ & 4 & 25 & 32 & 0.80 & 2.28 & 6.1 & 5.3 \\
3N1 & 6 & 32 & 32 & 0.80 & 2.26 & 7.7 & 6.7
\end{tabular}



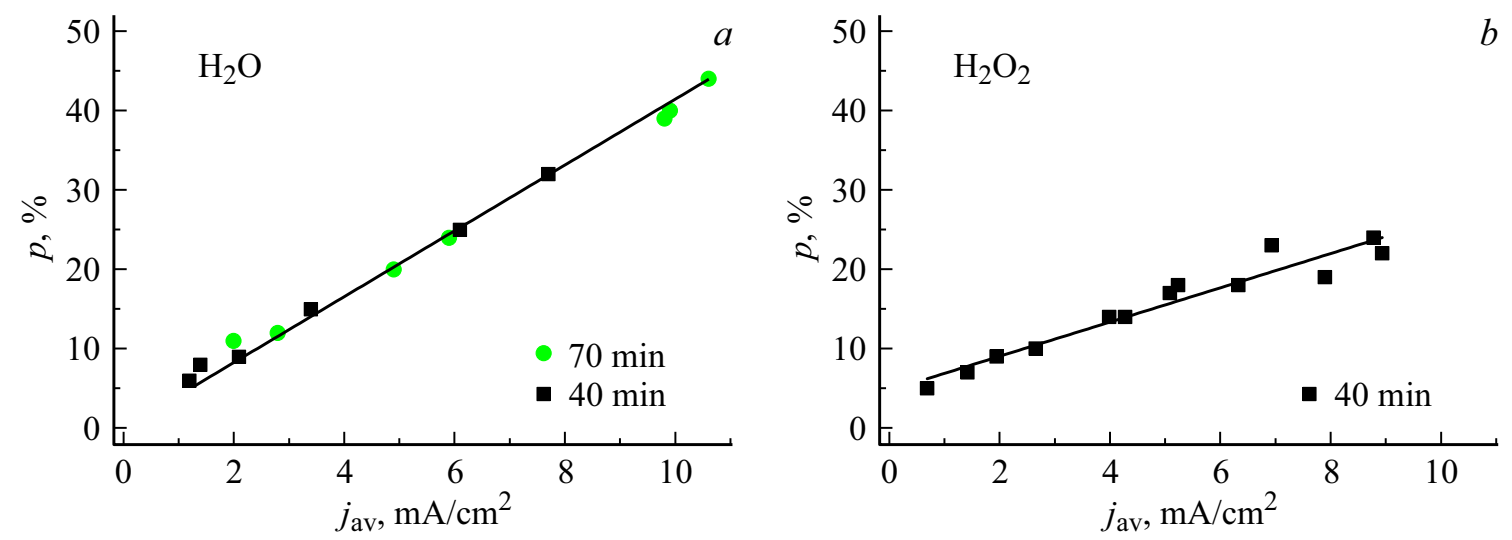

Рис. 11. Зависимость пористости от среднего во времени значения плотности тока травления для водного $(a)$ и перекисного $(b)$ электролита

творения Si ограничивается уже не величиной протекающего тока, а кинетикой реакции. Скорость $r$ в области насыщения для перекисного электролита в $\sim 2$ раза больше, чем для водного. Эффективная валентность растворения кремния (рис. 10,c) в водном электролите примерно постоянна $(n=2.2)$, а в электролите на основе перекиси водорода близка к 1 в темноте и возрастает с увеличением подсветки, оставаясь при этом всегда меньше 2. Это можно объяснить возрастающей ролью обычного двухвалентного механизма электрохимического растворения $\mathrm{Si}$ в HF. Этот механизм был предложен Геришером [22] и был модифицирован в последующих работах Коласинского [23,16]. Согласно этой модели, помимо инжекции дырки в валентную зону в процессе участвует дублирующий электрон, который инжектируется ионом фтора в зону проводимости кремния. Суммарный эффект состоит в удвоении числа электронов и проявляется как эффективная валентность $n=2$. На практике эффективная валентность обычно несколько выше 2, так как имеется вклад реакции с валентностью 4, присущей режиму электрополировки. Так, при формировании макропор в водном электролите на дне пор происходит электрополировка, что увеличивает эффективную валентность до 2.2-2.6 [3]. Изменение стехиометрии растворения $\mathrm{Si}$ в присутствии $\mathrm{H}_{2} \mathrm{O}_{2}$ объясняется тем, что дублирующий электрон захватывается молекулой $\mathrm{H}_{2} \mathrm{O}_{2}$ и не участвует в формировании протекающего тока. На рис. 10, $d$ приведена зависимость массы кремния, растворенного в результате анодной обработки, от $E$. Из нее видно, что анодное растворение в перекисном электролите происходит быстрее, чем в водном. С учетом примерно одинаковой пористости при невысоком уровне подсветки можно заключить, что ускоренное растворение кремния в перекисном электролите происходит в основном за счет более быстрого продвижения фронта в глубину. Уменьшение наклона зависимостей $p(E)$ и $\Delta m(E)$ при большой интенсивности света обусловлено возросшей эффективной валентностью, указывающей на то, что для растворения одного атома кремния требуется большее число носителей заряда.

Таким образом, мы видим, что электрохимическое растворение кремния в $\mathrm{HF}$ при наличии $\mathrm{H}_{2} \mathrm{O}_{2}$ характеризуется более высокой анизотропией, чем в отсутствие окислителя. Наиболее легко растворяются кристаллографические плоскости семейства (100), в результате чего макропоры, образующиеся в перекисном электролите, имеют более высокое аспектное отношение.

В водном электролите макропоры, образовавшиеся в пробойном режиме, мало отличаются от макропор, формирующихся при малых напряжениях, и поэтому следует ожидать, что для них также справедливо соотношение $p=j / j_{p s}[3]$, где $j_{p s}-$ критическая плотность тока перехода в режим электрополировки. Действительно, зависимость пористости от среднего по времени значения $j_{a v}$, как при $t=40$, так и при $t=70$ мин, ложится на одну прямую, проходящую через начало координат (рис. 11,a). Найденное из наклона этой прямой значение $j_{p s}=24.10 \mathrm{MA} / \mathrm{cm}^{2}$ хорошо согласуется с величиной, рассчитанной по формуле [3]:

$$
j_{p s}\left[\mathrm{MA} / \mathrm{cm}^{2}\right]=C_{p s} C_{\mathrm{HF}}^{1.5} \exp \left(-E_{a} / k_{\mathrm{B}} T\right),
$$

где $C_{p s}=3.3 \cdot 10^{6} \mathrm{мA} / \mathrm{cm}^{2} ; \quad E_{a}=0.345$ эВ - энергия активации; $T$ - температура электролита в градусах Кельвина, K; $C_{\mathrm{HF}}$ - концентрация $\mathrm{HF}$ в вес\%, $k_{\mathrm{B}}=8.6 \cdot 10^{-5}$ эВ/K - постоянная Больцмана. Для нашей концентрации 4\% HF и температуры $15^{\circ} \mathrm{C}$ расчет дает $j_{p s}=24.39 \mathrm{MA} / \mathrm{cm}^{2}$. Для перекисного электролита зависимость $p\left(j_{a v}\right)$ тоже ложится на прямую, но она не проходит через начало координат (рис. $11, b$ ). Конечная пористость, которая получается при экстраполяции тока к нулю $j_{a v}=0$, указывает на то, что травление кремния может происходить и без тока, т.е. чисто химическим путем.

Для того чтобы оценить влияние химического растворения $\mathrm{Si}$ в электролите на основе перекиси водорода был проведен эксперимент с двумя парами образцов. Анодирование этих образцов осуществлялось в одинаковых условиях при низком напряжении $U=1 \mathrm{~B}$ в течение 


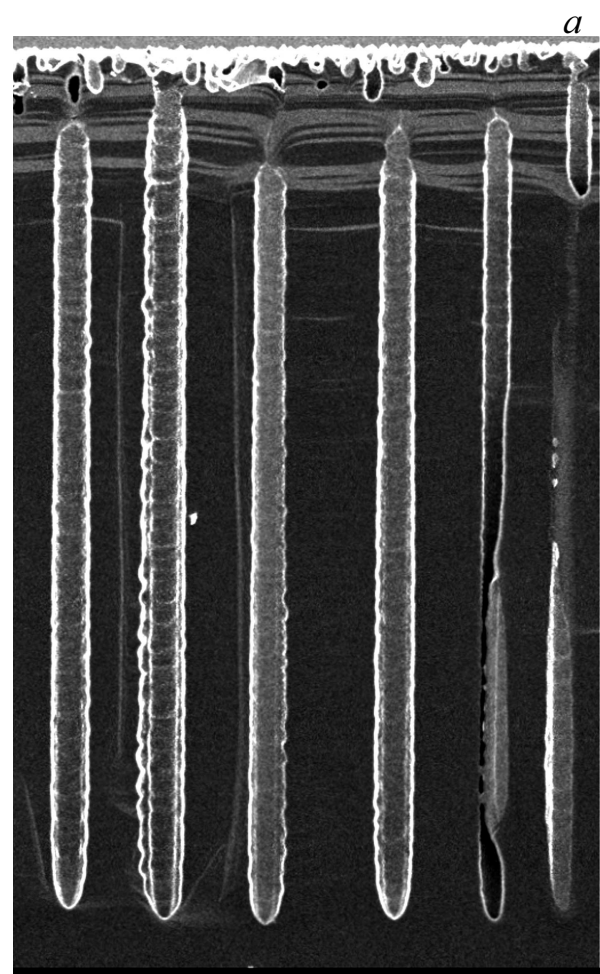

$a$

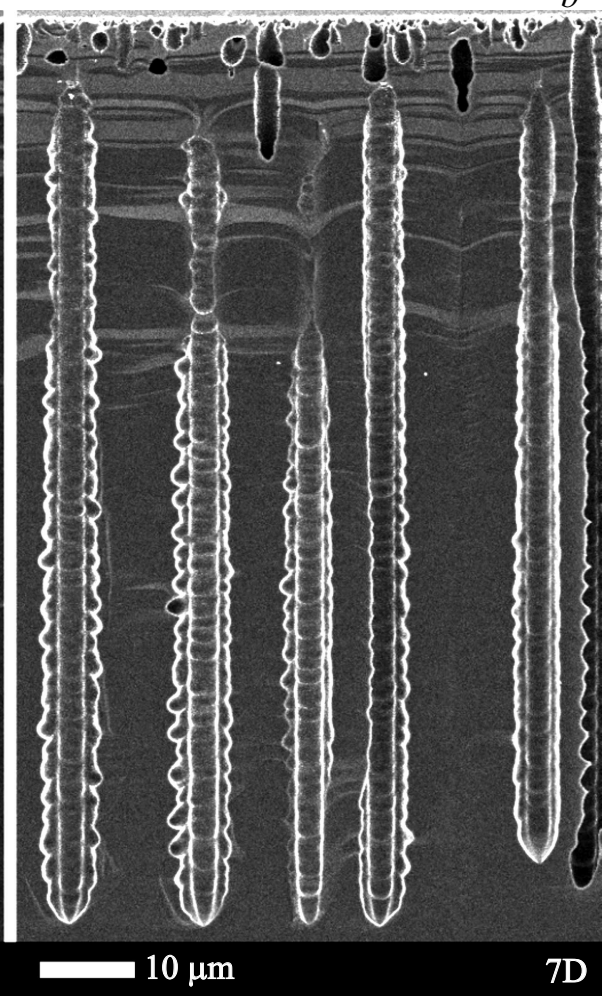

19In1

$c$

$d$

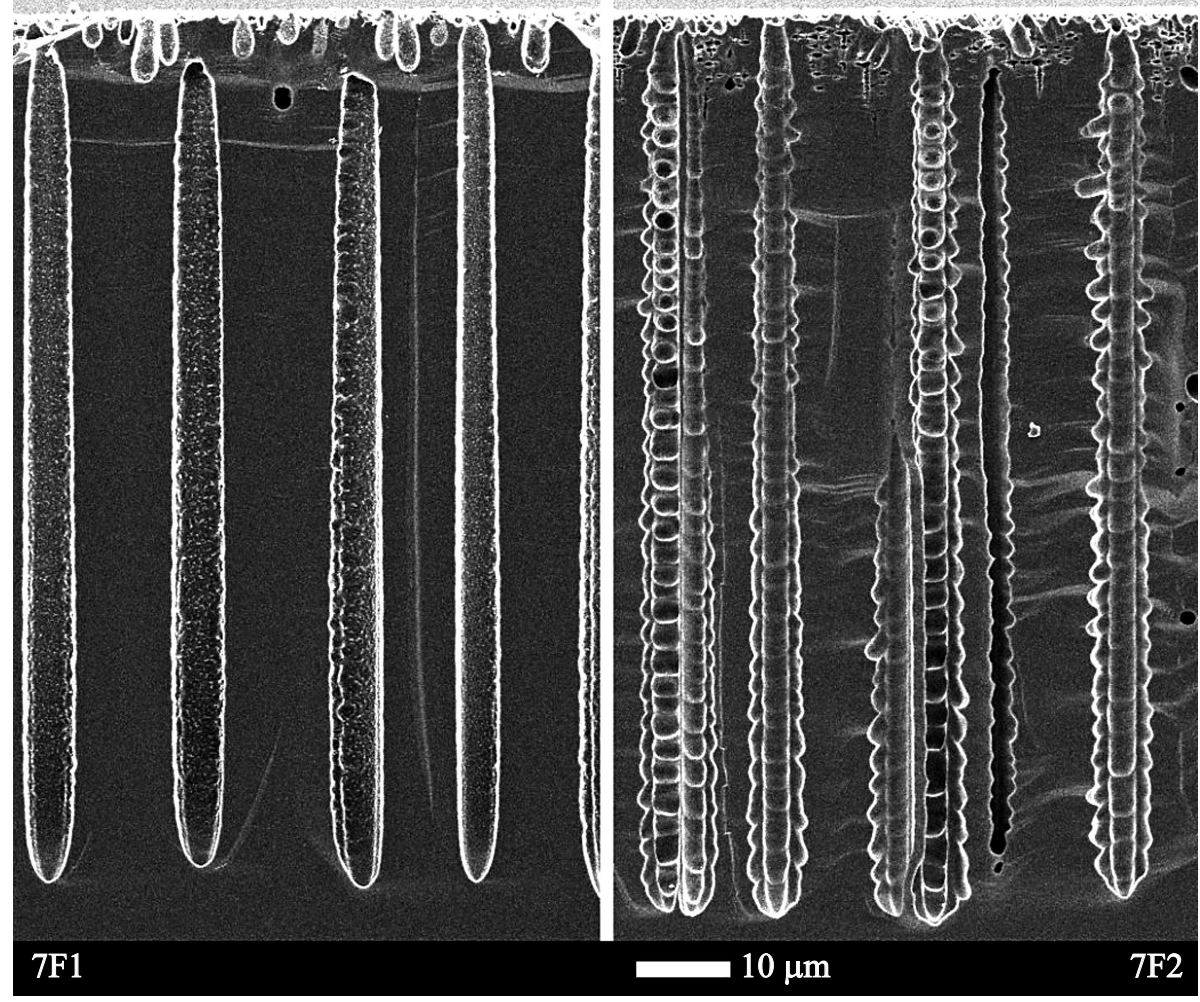

Рис. 12. Сравнение морфологии макропор, сформированных фотоанодированием в перекисном растворе с макропорами, подвергшимися дополнительному химическому травлению в том же электролите: $a$ и $c$ - образцы сразу после электрохимического травления $\left(U=1 \mathrm{~B}, j=5.7 \mathrm{MA} / \mathrm{cm}^{2}, T=15^{\circ} \mathrm{C}, t=60\right.$ мин), $b$ и $d-$ после дополнительной выдержки в перекисном электролите: в течение 5 ч при $T=15^{\circ} \mathrm{C}(b)$ и 28 ч при $T=22^{\circ} \mathrm{C}(d)$. 


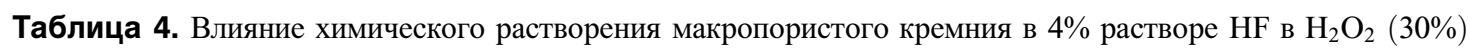

\begin{tabular}{|c|c|c|c|c|c|c|}
\hline \multirow{2}{*}{$\begin{array}{c}\text { № } \\
\text { образца }\end{array}$} & \multirow{2}{*}{$\begin{array}{c}\text { Анодирование } \\
t, \text { мин }\end{array}$} & \multicolumn{2}{|c|}{$\begin{array}{c}\text { Дополнительное } \\
\text { химическое травление }\end{array}$} & \multirow{2}{*}{$\begin{array}{c}\text { Суммарное изменение } \\
\text { массы } \Delta m, \text { мг }\end{array}$} & \multirow[t]{2}{*}{$l$, мкм } & \multirow[t]{2}{*}{$p, \%$} \\
\hline & & Время, ч & $T,{ }^{\circ} \mathrm{C}$ & & & \\
\hline 19In1 & 60 & 0 & 15 & 9.0 & 92 & 14.8 \\
\hline 7D & 60 & 5 & 15 & 9.6 & 96 & 15.2 \\
\hline $7 \mathrm{~F} 1$ & 60 & 0 & 15 & 8.7 & 98 & 13.5 \\
\hline $7 \mathrm{~F} 2$ & 60 & 28 & 22 & 14.6 & 101 & 22.2 \\
\hline
\end{tabular}

60 мин. в режиме постоянного тока $\left(j=5.7 \mathrm{MA} / \mathrm{cm}^{2}\right)$, когда постоянство тока в процессе электрохимического травления обеспечивалось за счет изменения интенсивности подсветки в диапазоне $E=3.8-2.0$. Для первой пары образцов 19In1 и 7D использовался уже неоднократно использованный электролит, для второй пары 7F1 и 7F2 - свежеприготовленный. Данные по этим образцам представлены в табл. 4. Изменение морфологии для обеих пар образцов показано на рис. 12 . После анодирования макропоры имеют вертикальные стенки, практически без ветвления (рис. 12, $a$ и с). Образцы сравнения для каждой пары после анодирования подверглись дополнительной выдержке в перекисном электролите, оставаясь в ячейке в условиях разомкнутой цепи и без освещения: при температуре $15^{\circ} \mathrm{C}$ в течение 5 ч для первой пары и при $T=22^{\circ} \mathrm{C}$ в течение 28 ч для второй. Из рис. 12 видно, что после отключения тока продолжается травление кремния, которое приводит к нарушению пассивации стенок макропор и появлению боковых ветвей, более выраженное для второй пары. Соответственно наблюдается большая потеря массы и большее возрастание пористости.

Из табл. 4 следует, что скорость химического растворения макропористого кремния при $22^{\circ} \mathrm{C} v=0.21$ мг/ч, а при $15^{\circ} \mathrm{C} v=0.12$ мг/ч. Сравнивая последнюю скорость со скоростью электрохимического растворения $(8.85$ мг/ч), можно заключить, что вклад чисто химического процесса составляет около $1 \%$, т.е. весьма мал. Ранее было установлено, что при наличии окислителей в электролите скорость химического растворения пренебрежимо мала [24]. В работе [11] скорость химического травления в смеси $\mathrm{HF}$ и $\mathrm{H}_{2} \mathrm{O}_{2}$ оценивалась на 3 порядка меньшей, чем электрохимического. Расхождение с нашим результатом возможно обусловлено более развитой поверхностью использовавшегося нами макропористого кремния по сравнению с беспористым.

Из рис. 12 и табл. 4 также видно, что свежий электролит (с более высоким содержанием неразложившейся перекиси водорода) в процессе анодирования изменяет внутреннюю поверхность макропор, делая ее более шероховатой, а при дополнительной бестоковой обработке выявляет у поверхности пробойные мезопоры.

Таким образом, роль окислителя в составе фторсодержащего электролита проявляется лишь при протекании тока, когда процесс растворения кремния и порообразо- вания инициируется появлением дырки в валентной зоне кремния.

\section{4. Заключение}

Фотоэлектрохимическое травление $n$-Si(100) в пробойном режиме при использовании 4\%-го раствора $\mathrm{HF}$ в 30\% перекиси водорода и в водном электролите с тем же содержанием HF показало, что наличие окислителя $\mathrm{H}_{2} \mathrm{O}_{2}$ обусловливает изменение стехиометрии реакций, определяющих электрохимическое растворение кремния, снижая эффективную валентность (выход по току) вплоть до $n=1$. В перекисном электролите в $\sim 2$ раза возрастает скорость роста основных каналов. Морфология пор в перекисном электролите также значительно отличается от того, что получается в водном электролите. Во-первых, возрастает аспектное отношение за счет уменьшения диаметра основных каналов и роста их глубины. Во-вторых, при высокой интенсивности подсветки появляются вторичные поры в виде наклонных ветвей, распространяющихся под углом $15-35^{\circ}$ к вертикальной оси каналов. Количество пробойных мезопор в перекисном электролите гораздо больше, чем в водном, что связано с ухудшением пассивации боковых стенок макропор. Несмотря на бо́льшую массу кремния, растворенного при фотоанодировании, пористость структур, полученных в перекисном электролите, равна или меньше той, что получается в случае водного электролита. Возрастание $n$ при повышении интенсивности света является причиной замедления роста $\Delta m(E)$ и $p(E)$.

Авторы выражают благодарность Д.Н. Горячеву, О.М. Сресели и В.П. Улину за прочтение рукописи и полезное обсуждение. Электронно-микроскопические исследования выполнены А.И. Лихачевым с использованием оборудования федерального ЦКП „Материаловедение и диагностика в передовых технологиях“, поддержанного Министерством образования и науки России (Уникальный идентификатор проекта RFMEFI62117X0018).

\section{Список литературы}

[1] L. Canham. Handbook of Porous Silicon (Switzerland, Springer Intern. Pub., 2014) pt V, p. 731. 
[2] M. Bassu, S. Surdo, L.M. Strambini, G. Barillaro. Adv. Funct. Mater., 22, 1222 (2012).

[3] V. Lehmann. Electrochemistry of Silicon (Weinheim, Wiley-VCH, 2002).

[4] T. Trifonov A. Rodr'iguez, L.F. Marsal, J. Pallares, R. Alcubilla. Sensors Actuators A, 141, 662 (2008).

[5] X.Q. Bao, J.W. Jiao, Y.L. Wang, Y. Zhang, D.H. Ge, Kyoung Won Na, H. Choi. Electrochem. Commun., 9, 1491 (2007).

[6] C. Cozzi, G. Polito, L.M. Strambini, G. Barillaro. Electrochimica Acta, 187, 552 (2016).

[7] Z. Huang, N. Geyer, P. Werner, J. Boor, U. Gösele. Adv. Mater., 23, 285 (2011).

[8] Д.Н. Горячев, Л.В. Беляков, О.М. Сресели. ФТП, 37 (4), 494 (2003).

[9] M. Christophersen, J. Cartensen, H. Föll. Phys. Status Solidi A, 182, 45 (2000).

[10] Y.H. Ogata, A. Koyama, F.A. Harraz, M.S. Salem, T. Sakka. Electrochemistry, 75, 270 (2007).

[11] X.Q. Bao, J.W. Jiao, Y.L. Wang, K. W. Na, H. Choi. J. Electrochem. Soc., 154 (3), D175 (2007).

[12] X.Q. Bao, J.W. Jiao, J. Zhou, Y.L. Wang. Electrochimica Acta, 52, 6728 (2007).

[13] X.Q. Bao, J.W. Jiao, Y.L. Wang, K.W. Na, H. Choi. Phys. Status Solidi A, 204 (7), 2287 (2007).

[14] F.A. Harraz, S.M. El-Sheikh, T. Sakka, Y.H. Ogata. Electrochimica Acta, 53, 6444 (2008).

[15] D.H. Ge, J.W. Jiao, S. Zhang, Y.L. Wang. Electrochem. Commun., 12, 603 (2010).

[16] C. Cozzi, G. Polito, K.W. Kolasinski, G. Barillaro. Adv. Funct. Mater., 27, 1604310 (2017).

[17] C. Cozzi, G. Polito, K.W. Kolasinski, G. Barillaro. ECS Transactions, 77 (5), 199 (2017).

[18] Е.В. Астрова, Н.Е. Преображенский, Г.В. Ли, С.И. Павлов. ФТП, 52 (3), 414 (2018).

[19] C. Jager, B. Finkenberger, W. Jager, M. Christophersen, J. Carstensen, H. Foll. Mater. Sci. Eng. B, 69-70, 199 (2000).

[20] H. Foll, M. Christophersen, J. Carstensen, G. Hasse. Mater. Sci. Eng. R, 39 (4), 93 (2002).

[21] S. Lolkes, M. Christophersen, S. Langa, J. Carstensen, H. Foll. Mater. Sci. Eng. B, 101, 159 (2003).

[22] H. Gerischer, P. Allongue, V.C. Kieling. Ber. Bunsenges. Phys. Chem., 97, 753 (1993).

[23] K.W. Kolasinski. Surf. Sci., 603, 1904 (2009).

[24] M. Christophersen, J. Cartensen, H. Föll. Phys. Status Solidi A, 182, 45 (2000).

\section{Influence of hydrogen peroxide on the photoanodization of $n-\mathrm{Si}$ in the breakdown mode}

\author{
G.V. Li, E.V. Astrova, A.I. Lihachev \\ loffe Institute, \\ 194021 St. Petersburg, Russia
}

\begin{abstract}
We report on experimental study of anodization of solar grade low-doped $n$ - $\mathrm{Si}(100)$ in an electrolyte consisting of a $4 \%$ HF solution in $30 \%$ hydrogen peroxide at a voltage higher than the breakdown voltage. We have studied influence of the back side illumination intensity on the morphology of the porous structure and the following parameters as porosity, effective valence and dissolution rate of silicon. The obtained data are compared with the data for samples subjected to photoanodization in an aqueous electrolyte of the same HF concentration. It has been found that the presence of hydrogen peroxide significantly changes the morphology of macropores, increases their growth rate in depth of the substrate to 2 times and reduces their diameter. In the presence of hydrogen peroxide, we observed appearance of secondary pores inclined to the axis of the main channel to $15-35^{\circ}$ and an increase in the number of breakdown mesopores located in the $\langle 100\rangle$ directions in a plane parallel to the sample surface. The silicon dissolution valence in $\mathrm{HF}: \mathrm{H}_{2} \mathrm{O}_{2}$ at low illumination is close to unity. It increases with the intensity of light, indicating a decrease in the contribution of a monovalent reaction due to the presence of an oxidizer, but always remains less than 2 .
\end{abstract}

